\title{
East Africa Region Energy Projection with the Carbon Emissions for Conventional Energy
}

\author{
Aissa Boudjella ${ }^{1,2 *}$, Mwongereza Jean d'Amour ${ }^{3,4^{*}}$ \\ ${ }^{1}$ American University, Darulaman Road Kabul Afghanistan, Kabul, Afghanistan \\ ${ }^{2}$ Bircham International University, Avda Sierra 2, Villanueva de la Cañada, Madrid, Spain \\ ${ }^{3}$ Pan African University Institute of Water and Energy Science PAUWES, Pole Chetouane, Tlemcen, Algeria \\ ${ }^{4}$ Integrated Polytechnic Regional Centre East (IPRC-EAST), Kibungo, Rwanda \\ Email: aboudjella@auaf.edu.af, boudjellaa@bircham.edu,jmwongereza@yahoo.fr
}

How to cite this paper: Boudjella, A. and d'Amour, M.J. (2018) East Africa Region Energy Projection with the Carbon Emissions for Conventional Energy. Computational Water, Energy, and Environmental Engineering, 7, 69-79.

https://doi.org/10.4236/cweee.2018.72004

Received: January 26, 2018

Accepted: April 25, 2018

Published: April 28, 2018

Copyright $\odot 2018$ by authors and Scientific Research Publishing Inc. This work is licensed under the Creative Commons Attribution International License (CC BY 4.0).

http://creativecommons.org/licenses/by/4.0/ Open Access

\begin{abstract}
In this study we analyzed the generation and the potential of the electricity capacity of energy mix in East Africa from 2020 to 2040 including $\mathrm{CO}_{2}$ emission. The predicted results show that the electricity generated from hydro will dominate compared to gas, oil, coal, Solar PV, bio-energy and other renewable energy. Some forms of energies such as bio-energy, solar PV will contribute less, while the contribution of nuclear will remain insignificant. The oil will continue to emit a lot carbon dioxides compared to the emission from gas and coal. The emission of $\mathrm{CO}_{2}$ from total final consumption (TFC) of oil will be high compared to its emission from power generation (PG) of oil. More importantly, the results show a linear relationship between the energy outlook and time. This approach of modeling the energy in a linear form simplifies significantly the analysis of the electricity generation and capacity. Due to this high emission of $\mathrm{CO}_{2}$, a new policy and a transition from conventional to renewable should be implemented with clean and energy efficiency technology.
\end{abstract}

\section{Keywords}

East Africa, Electricity Generation, Electrical Capacity, Renewable Energy, Carbon Dioxide Emissions

\section{Introduction}

Africa continent currently has $147 \mathrm{GW}$ installed capacity which is comparable to what china installs in less than two years. The average energy consumption per-capita in Sub-Saharan Africa (excluding South-Africa) is $153 \mathrm{Kwh}$ per year

* These authors contribute equally to this work. 
which is one fourth of the consumption in India and just $6 \%$ of the global average. Nearly 600 million people in Africa lack access to electricity [1]. East Africa (EA) encompasses all countries located in Eastern region of Africa. Currently, over $81 \%$ of the population in the five EA countries has no access to modern energy services. Most of East African countries use traditional biomass burnt in open three-stone stoves which exposes the users to health hazards from indoor smoke and fire hazards, and results to rapid deforestation [2]. The lack of access to energy due to many reasons such as financial, instability, security, no strong policies implantation in energy sector, are a big challenge in those countries. However, some efforts were put in place to increase accessibility to energy whereby energy sector was strengthened. East Africa has enormous energy potential including solar, wind, hydro, geothermal, biomass and fossil fuels [3]. Harnessing the potential of these resources can help to address the energy demand gap.

In 2010, about 590 million African people (57\% of the population) had no access to electricity, and 700 million (68\% of the population) were living without clean cooking facilities. Africans currently consume only one quarter of the global average energy per capita, using a mix of hydropower, fossil fuels and biomass mostly in traditional uses [4]. If these current energy access trends continue, in 2030 there will still be 655 million people in Africa (42\% of the population) without access to power, and 866 million (56\% of the population) without clean cooking facilities, depriving the majority of the population of the opportunity to pursue a healthy and productive life [4]. By 2050, the population of the continent will be at least 2 billion people, twice as many as today, with $40 \%$ living in rural areas [4].

Africa population is growing rapidly, and its economies are developing and diversifying. In order to be sustained, this growth will need to be fuelled by a massive investment in energy [4].

East Africa is growing fast, as are its power needs. In the next two decades, electricity demand in the region is expected to quadruple to pursue a healthy and productive life. Providing full electricity access to all Africans would require only an additional 900 TWh over 20 years, an amount that corresponds to one year of current additional global power consumption [4].

The present study was based on the evaluation of the electricity generation, electrical capacity, carbon emission from power generation and total energy consumption. It projects also what will be the outcome of those energy subsectors up to 2040. This work will focus on both power generation and total final consumption (TFC) in East Africa region. The data obtained from International Energy Agency report of 2014 in African century case is analyzed, including electricity generation, electricity capacity and carbon emissions [5]. We examined the future projection of these forms of energy and how these forms of energy will be used up to 2040. This finding will help policies makers in this region to set strong measures to mitigate emission from use on conventional energy. Correlation between these forms of energy against time will be also pre- 
sented.

\section{Electricity Generation and Installed in East Africa Region}

East Africa region (EA) is one of the five regions of Africa continent which is composed by 14 countries. The access to electricity in this region is below compared to other regions. The biomass is the major primary energy used, especially for cooking and heating. In this region many countries have high potential resources but still not exploitable. There are potential in hydro, wind, solar irradiation, bio-energy and some of them have oil and natural gas reserves. The installed capacity in 2010 was more than $38 \mathrm{GW}$ where 160 TWh of electricity generation came from gas-fired power plant [6] (IRENA). Electricity importation in this region is still low. However, some countries such as Burundi and Rwanda import electricity from DRC (Democratic Republic of Congo). East Africa has the highest geothermal potential in Africa where Kenya is dominating country. Ethiopia is reading for hydro potential in the region. According to African century case, the projection shows that this region will generate 310 TWh for energy mix.

\section{East Africa: African Century Case}

\subsection{Electricity Generation and Electrical Capacity}

The summarized data of electricity generation and trade with electrical capacity projection of East Africa are indicated in the Tables 1-6 [5]. The data show the contribution of different forms of energies and forecast them up 2040. It summarizes the power generation, trade, the electricity mix, the electricity capacity, $\mathrm{CO}_{2}$ emission and trade.

\subsection{Carbon Dioxide Emissions}

Some countries have gas [7] (Algeria, Angola, Benin, Botswana, Cameroon, Gabon, Ghana etc.) and oil (Algeria, Angola, Bahrain, Cameroon, Congo Republic,

Table 1. Electricity generation and trade (TWh) —East-Africa [5].

\begin{tabular}{cccccc}
\hline & 2020 & 2025 & 2030 & 2035 & 2040 \\
\hline Coil & 3 & 10 & 16 & 23 & 29 \\
Oil & 9 & 10 & 12 & 15 & 25 \\
Gas & 4 & 9 & 13 & 23 & 41 \\
Nuclear & - & - & - & - & - \\
Hydro & 35 & 52 & 77 & 111 & 151 \\
Bio-energy & 2 & 4 & 6 & 8 & 10 \\
Solar PV & 1 & 1 & 3 & 6 & 60 \\
Other renewables & 8 & 14 & 23 & 38 & -18 \\
Net imports & -1 & -6 & -8 & -12 & 310 \\
\hline Total Generation & 61 & 94 & 142 & 212 & 6 \\
\hline
\end{tabular}


Table 2. Electricity mix generation and trade in (\%)-East-Africa [5].

\begin{tabular}{cccccc}
\hline & $\mathbf{2 0 2 0}$ & $\mathbf{2 0 2 5}$ & $\mathbf{2 0 3 0}$ & $\mathbf{2 0 3 5}$ & $\mathbf{2 0 4 0}$ \\
\hline Coil & $4.92 \%$ & $10.64 \%$ & $11.27 \%$ & $10.85 \%$ & $9.35 \%$ \\
Oil & $14.75 \%$ & $10.64 \%$ & $8.45 \%$ & $7.08 \%$ & $8.06 \%$ \\
Gas & $6.56 \%$ & $9.57 \%$ & $9.15 \%$ & $10.85 \%$ & $13.23 \%$ \\
Nuclear & $0.00 \%$ & $0.00 \%$ & $0.00 \%$ & $0.00 \%$ & $0.00 \%$ \\
Hydro & $57.38 \%$ & $55.32 \%$ & $54.23 \%$ & $52.36 \%$ & 48.71 \\
Bioenergy & $3.28 \%$ & $4.26 \%$ & $4.23 \%$ & $3.77 \%$ & $3.23 \%$ \\
Solar PV & $1.64 \%$ & $1.06 \%$ & $2.11 \%$ & $2.83 \%$ & $3.87 \%$ \\
Other renewables & $13.11 \%$ & $14.89 \%$ & $16.20 \%$ & $17.92 \%$ & $19.35 \%$ \\
Net imports & $-1.64 \%$ & $-6.38 \%$ & $-5.63 \%$ & $-5.66 \%$ & $-5.81 \%$ \\
\hline
\end{tabular}

Table 3. Electrical capacity (GW)-East-Africa [5].

\begin{tabular}{cccccc}
\hline & $\mathbf{2 0 2 0}$ & $\mathbf{2 0 2 5}$ & $\mathbf{2 0 3 0}$ & $\mathbf{2 0 3 5}$ & $\mathbf{2 0 4 0}$ \\
\hline Coal $(\mathrm{GW})$ & 1 & 2 & 4 & 5 & 7 \\
Oil (GW) & 5 & 5 & 6 & 7 & 9 \\
Gas (GW) & 1 & 3 & 5 & 8 & 12 \\
Nuclear (GW) & $\mathrm{NA}$ & $\mathrm{NA}-$ & $\mathrm{NA}-$ & $\mathrm{NA}-$ & $\mathrm{NA}-$ \\
Hydro & 8 & 12 & 17 & 25 & 35 \\
Bio-energy & 0 & 1 & 1 & 1 & 2 \\
Solar PV & 0 & 1 & 2 & 4 & 8 \\
Other Renewables & 2 & 3 & 4 & 7 & 11 \\
Total Capacity & $\mathbf{1 7}$ & $\mathbf{2 7}$ & $\mathbf{3 9}$ & $\mathbf{5 7}$ & $\mathbf{8 4}$ \\
\hline
\end{tabular}

Table 4. Electrical capacity mix in (\%)-East-Africa [5].

\begin{tabular}{cccccc}
\hline & 2020 & 2025 & 2030 & 2035 & 2040 \\
\hline Coal & $5.88 \%$ & $7.41 \%$ & $10.26 \%$ & $8.77 \%$ & $8.33 \%$ \\
Oil & $29.41 \%$ & $18.52 \%$ & $15.38 \%$ & $12.28 \%$ & $10.71 \%$ \\
Gas & $5.88 \%$ & $11.11 \%$ & $12.82 \%$ & $14.04 \%$ & $14.29 \%$ \\
Nuclear & $0.00 \%$ & $0.00 \%$ & $0.00 \%$ & $0.00 \%$ & $0.00 \%$ \\
Hydro & $47.06 \%$ & $44.44 \%$ & $43.59 \%$ & $43.86 \%$ & $41.67 \%$ \\
Bio-energy & $0.00 \%$ & $3.70 \%$ & $2.56 \%$ & $1.75 \%$ & $2.38 \%$ \\
Solar PV & $0.00 \%$ & $3.70 \%$ & $5.13 \%$ & $7.02 \%$ & $9.52 \%$ \\
Other Renewable & $11.76 \%$ & $11.11 \%$ & $10.26 \%$ & $12.28 \%$ & $13.10 \%$ \\
\hline
\end{tabular}

Table 5. $\mathrm{CO}_{2}$ Emissions (Mt)-East-Africa[5].

\begin{tabular}{cccccc}
\hline & $\mathbf{2 0 2 0}$ & $\mathbf{2 0 2 5}$ & $\mathbf{2 0 3 0}$ & $\mathbf{2 0 3 5}$ & $\mathbf{2 0 4 0}$ \\
\hline Coal & 9 & 18 & 28 & 39 & 54 \\
Oil & 52 & 66 & 85 & 113 & 151 \\
Gas & 1 & 3 & 5 & 8 & 14 \\
Total $\mathrm{CO}_{2}^{\#}$ & $\mathbf{6 2}$ & $\mathbf{8 7}$ & $\mathbf{1 1 8}$ & $\mathbf{1 6 0}$ & $\mathbf{2 1 9}$ \\
\hline
\end{tabular}


Table 6. Emissions of $\mathrm{CO}_{2}(\mathrm{PG})$ and (TFC) in (Mt)-East-Africa [4].

\begin{tabular}{cccccc}
\hline & $\mathbf{2 0 2 0}$ & $\mathbf{2 0 2 5}$ & $\mathbf{2 0 3 0}$ & $\mathbf{2 0 3 5}$ & $\mathbf{2 0 4 0}$ \\
\hline Coal (PG) & 3 & 10 & 17 & 23 & 30 \\
Oil (PG) & 6 & 7 & 9 & 12 & 19 \\
Gas (PG) & 1 & 3 & 5 & 8 & 14 \\
Coal (TFC) & 5 & 8 & 11 & 16 & 24 \\
Oil (TFC) & 46 & 59 & 76 & 101 & 132 \\
Gas (TFC) & 0 & 0 & 0 & 0 & 0 \\
\hline
\end{tabular}

Ivory Cost, Egypt, Ghana etc.) [8], which most are used to produce electricity. Electricity generation through gas-and oil-fired power plants that dominates. This results in a high carbon emission. Emissions also come from burning coal and gas as well as from the transport due to high use of diesel.

Table 5 \& Table 6 summarize the projection contribution of carbon emissions from both power generation and total final consumption of coal, oil and gas.

\section{Results and Discussion}

Sub-Saharan Africa has the lowest electrification level in the world [9]. It is largely reliant on traditional biomass which is termed as combustible renewables and wastes [10] [11]. Although South Africa accounts for less than $10 \%$ of 9 sub-Saharan African's population, its use of electricity is almost three times higher than that of sub-Saharan Africa. North Africa, whose population is less than a third of sub-Saharan Africa, consumes more than one and half times the petroleum products consumed in sub-Saharan Africa [10] [11]. Firewood remains the most common cooking fuel in most of Sub-Saharan Africa [12] [13] [14].

The report shows the contribution of different forms of energies and forecast them from 2020 up to 2040 . It summarizes the power generation, electrical capacity and emissions of carbon dioxide from power generation and total energy consumption from different sectors. The variation in electricity generation of these forms of energy and trade are illustrated in Figure 1 and Figure 2, respectively. The slope a) and the y-intercept b) of the linear regression of Figure 1 and Figure 3 are shown in Table 7 and Table 8, respectively.

The energy model in Figure 1 shows that hydro, coal, oil, gas, bio-energy and solar energy continue to increase at different rate from 2020 to 2040. Hydro with high rate (slope $\mathrm{a}=5.8$ ) will play a big role in electricity generation and will continue to increase rapidly compared to other forms of energies. Starting from 2020 , other forms of energies will appear and continue to increase at different rate as indicated by their slope in the Table 7 . The contribution of nuclear in energy generation will not contribute significantly. The share of solar PV in energy generation will increase slowly compared to other resources. From 2020 


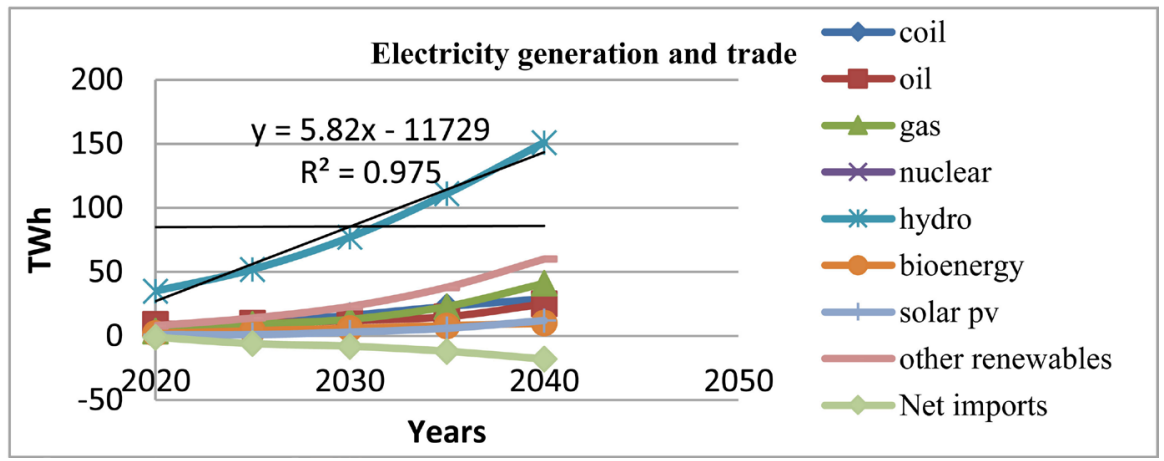

Figure 1. Electricity generation from 2020 to 2040. Source: Africa Energy Outlook 2014 $[5]$.

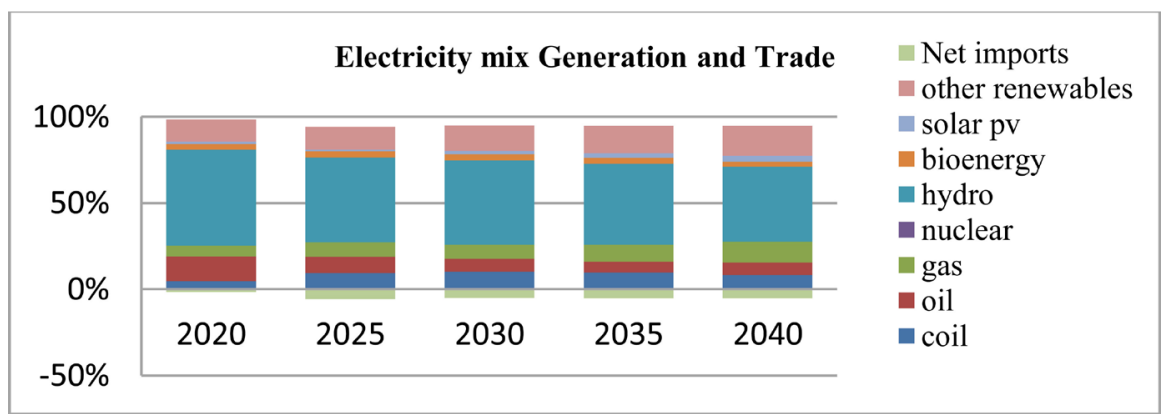

Figure 2. Electricity mix generation from 2020 to 2040. Source [5].

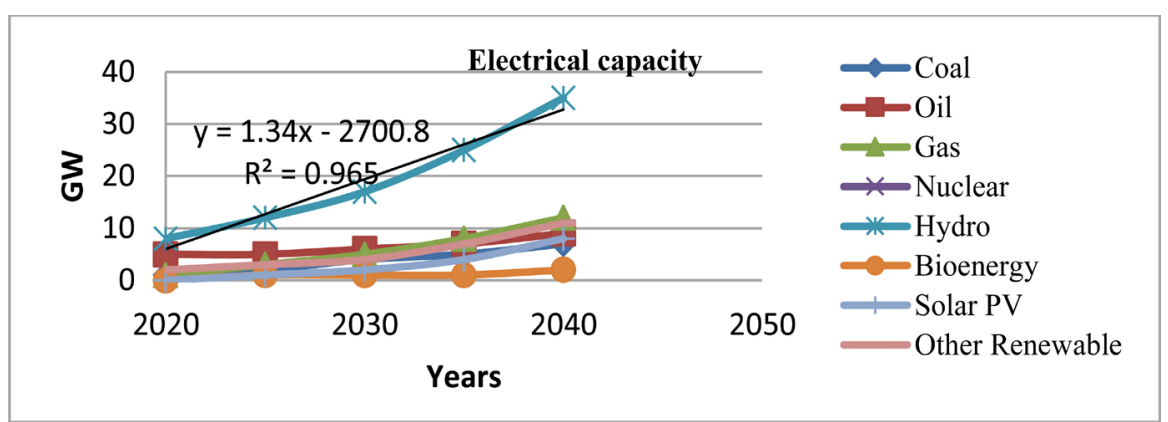

Figure 3. Electrical capacity from 2020 to 2040. Source: Africa Energy Outlook 2014 [5].

Table 7. Slopes, y-intercept and R-square for Electricity generation and trade obtained from Figure 1.

\begin{tabular}{cccc}
\hline & Slope (a) & $\mathbf{b}$ & $\mathbf{R}^{2}$ \\
\hline Coal & 1.3 & -2622.8 & 0.9993 \\
Oil & 0.74 & -1488 & 0.8207 \\
Gas & 1.76 & -3554.8 & 0.9047 \\
Hydro & 5.8 & -11729 & 0.975 \\
Bio-energy & 0.4 & 806 & 1 \\
Solar PV & 0.54 & -1091.6 & 0.8556 \\
Other Renewables & 2.56 & -5168.2 & 0.9399 \\
Net Imports & -0.8 & 1615 & 0.9756 \\
\hline
\end{tabular}


Table 8. Slope, y intercept and R-squared for Electricity capacity obtained from Figure 3.

\begin{tabular}{cccc}
\hline & Slope (a) & b & $\mathbf{R}^{2}$ \\
Coal & 0.3 & -605.2 & 0.9868 \\
Oil & 0.2 & -399.6 & 0.8929 \\
Gas & 0.54 & -1090.4 & 0.9746 \\
Hydro & 1.34 & -2700.8 & 0.965 \\
Bio-energy & 0.08 & -161.4 & 0.8 \\
Solar PV & 0.38 & -768.4 & 0.9025 \\
Other Renewable & 0.44 & -887.8 & 0.9098 \\
\hline
\end{tabular}

the exportation of electricity also will increase after meeting the energy demand. Other renewables also will increase their contribution in electricity generation. Bio-energy and solar PV will contribute less in energy mix comparing with other source of electricity generation. The contribution of gas will increase slightly after hydro and other renewable energy. Linear regression equations of these forms of energy mix are indicated in Table 7.

Figure 2 shows the $\%$ of electricity mix generation and trade for each year. Hydro is followed by other renewables and oil will contribute a lot in power generation. According to whole projection, the contribution for other renewables energy in electricity mix generation and trade will continue to increase.

In Figure 3, the electricity capacity will continue to increase at different rate as indicated in Table 8 whereby hydro will play an important role compared with other forms of energy. The contribution of nuclear capacity will be insignificant as indicated in the graph. In 2040 hydro and gas capacity will be high compared with other forms of energy. Bio-energy will increase slowly in electrical capacity with regard to other source of power. This increase of hydro in electrical capacity may be due to high potential in this region.

Countries with no natural resources should develop hydro because is cheaper compared to other renewables energy. The low contribution of Bio-energy in this shared energy may be explained by the implementation of expensive technology compare to diesel. The bio-energy which is made from crops requires a lot of land. Some countries like Rwanda and Burundi are very small and the implementation of this technology will be difficult to be adapted.

Figure 4 shows the electrical mix capacity from 2020 to 2040 in term of energy $\%$. In general the contribution of oil will be likely reduced up to 2040.Apart from 2030 and 2035, hydro will probably decrease with low contribution rate, whereas the contribution of nuclear will be insignificant. The energy generated from bio-energy will probably decrease and then increase a little bit in 2040 . From 2030, other forms of energy such as hydro, other renewables and coal in electrical mix capacity will most likely remain constant. In contrast to the coal, other renewables will continue to increase. 
Linear regressions for $\mathrm{CO}_{2}$ emissions for coil, oil and gas are indicated in Figure 5. The emission of carbon dioxide from oil will probably dominate other emission (from coal and gas). The gas will emit less compared with coal and oil. This high emission is due to more usage of oil than coal and gas. Day to day, the oil is transformed in many forms which are mainly necessary energy need. Oil is used for electricity generation, transport and lighting that why emissions from oil will continue to dominate emissions from coal and gas.

In Figure 6, the emission from total final consumption (TFC) of oil will dominate other emission from both power generation (PG) and TFC of other

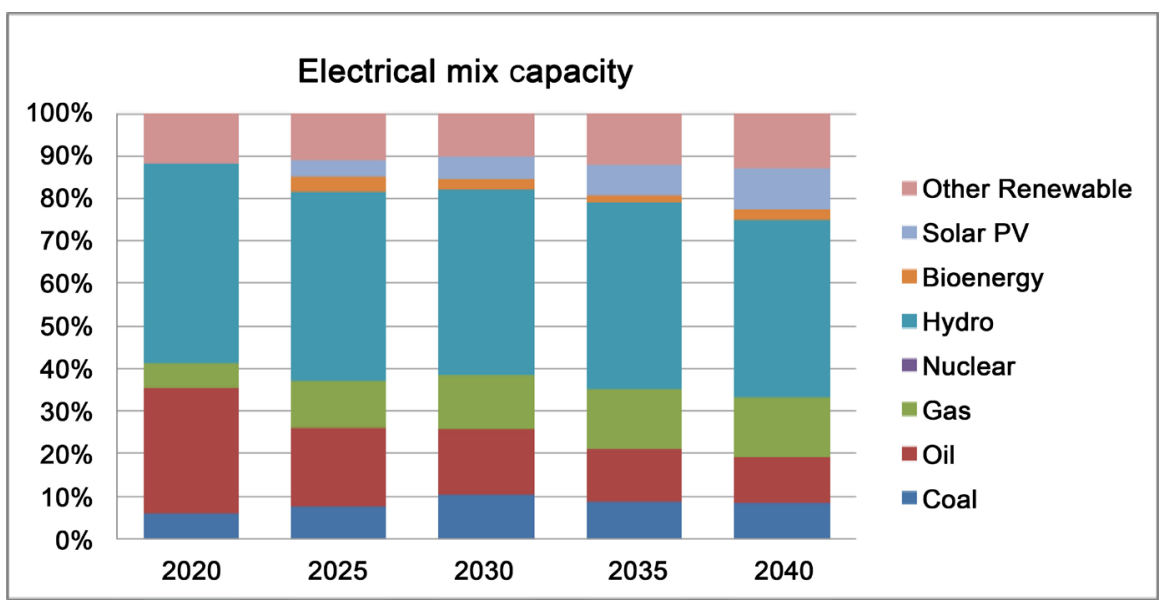

Figure 4. Electrical mix capacity from 2020 to 2040. Source: Africa Energy Outlook 2014 [5].

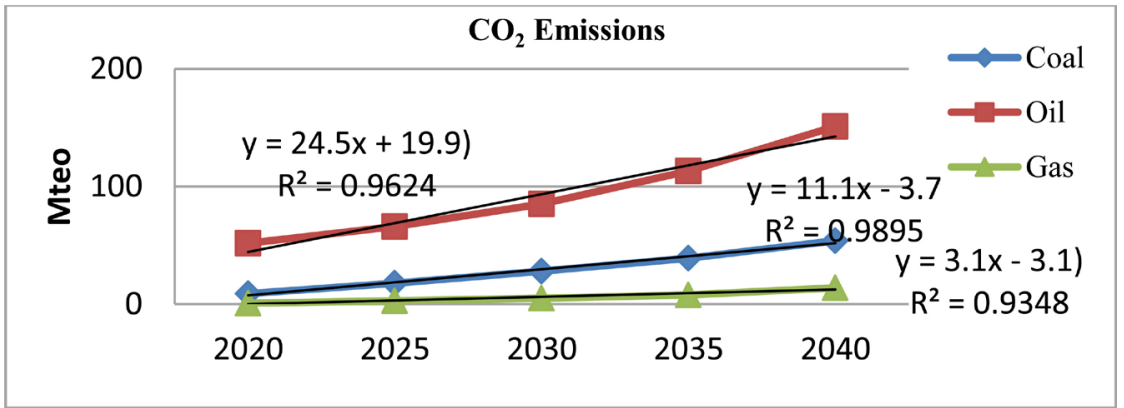

Figure 5. Carbon dioxide emissions from 2020 to 2040 [5].

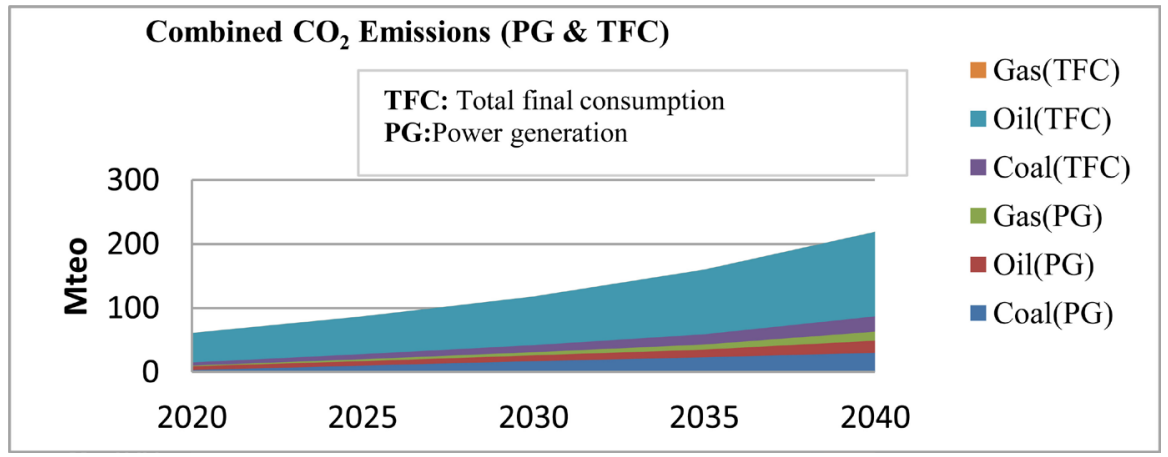

Figure 6. Combined carbon dioxide emissions from 2020 to 2040. Source [5]. 
sources. The emission from power generation of gas will be less compared to coal and oil. Emissions from power generation of coal will dominate in comparison with the emissions from TFC of coal. In the projection only emission from power generation of gas will appear.

Many sub-Saharan African countries do not have reliable databases on traditional biomass energy supply and household energy use. This makes it difficult to formulate appropriate policy and field-oriented interventions. Mechanisms for collection and documentation of data on traditional biomass supply and household energy consumption, which is regularly updated and validated, need to be instituted [10].

Many policy analysts stress the need for aggressive dissemination of improved biomass technologies (IBTs) in sub-Saharan Africa, to mitigate the negative effects of traditional biomass energy use-particularly indoor air pollution that is linked to respiratory diseases, one the main causes of death for children under the age of five. Sub-Sahara African governments should put in place policies that support the development and dissemination of IBTs [15] [16]. Private sector, NGOs, CBOs and donor organizations should implement projects aimed at ensuring the rapid dissemination of these IBTs. In particular, efforts to reduce the cost of widely used IBTs such as improved cook stoves should be accelerated, so that they are within the reach of even the poorest of the poor in sub-Saharan Africa [17] [18].

Africa is undergoing unprecedented sustained period of economic growth and transformation. Starting from 2020, other forms of energies will appear and continue to increase at different rate. The international trade of electricity in this region will appear in 2020 and continue to increase as predicted by the data. Up to 2040, hydro will play a big role in electricity generation with other renewable energy sources, such as coal, oil, Gas, bio-energy and solar PV that will continue to increase at different rate (Table 7 and Table 8). The share of solar PV in energy generation will slowly increase compared to other sources. The capacity of hydro and renewable energy sources will be high compared with other sources such as bioenergy, coal, oil, PV solar, and gas. The results show also that bio-energy will increase slowly in electricity generation in comparison with other source of energies. The present report shows that oil will continue to emit a lot carbon dioxide compared to gas and coal. The emission of $\mathrm{CO}_{2}$ from total final consumption (TFC) of oil will continue to be high in comparing with $\mathrm{CO}_{2}$ emission from power generation (PG) of oil. From 2025 until 2040, the emission of carbon dioxide from power generation of coal will be high compared with emission of $\mathrm{CO}_{2}$ generated from FTC of coal. In this period, the emission from TFC for gas will remain insignificant. The total final consumption emission of oil in general will dominate other emissions from both coal and gas. Due to this high emission of $\mathrm{CO}_{2}$, new technologies should be introduced in order to reduce gas pollution from TFC. This study demonstrates that the $\mathrm{CO}_{2}$ emissions, the electricity generation and electricity capacity, which are an indicator of the economic growth can be described by a linear regression. Their magnitudes, the ex- 
tracted parameters shown in Table 7 and Table 8 may be useful to assess the sustained economic development and transformation that require a definition of electricity access in those countries.

\section{Conclusions}

The contribution of hydro will continue to dominate other forms of energies for both electricity generation and electricity capacity. In general bio-energy will probably contribute less including other forms of energies. For electricity generation, the exportation of energy will be likely to increase. For the conventional energy (gas and oil), the emission of carbon dioxide from total final consumption of oil will continue to dominate from both total final consumption and power generation of energy. Apart from hydro, more investments are required in this region for exploiting the resources of renewables. In long term, due to climate change and global warning, the electricity generated from Hydro is not reliable source. Policy makers in this region should provide a road map that encourages and facilitates to invest more in renewable energy. The reduction of emissions from both power generation and total final consumption should be prioritized by introducing the use of resources that generate low $\mathrm{CO}_{2}$ emissions. Countries in this region with big land should develop the use of bio-energy, especially for transport and lighting to reduce the level of emissions. More technologies should be introduced in carbon dioxide emissions reduction by increase the energy efficiency and energy conservation.

The results show that the relationship between the projections of energy mix and $\mathrm{CO}_{2}$ emissions can be described by a linear regression. The magnitude of extracted parameters namely the slope and y intercept may be used as guideline to asses and evaluate the generation electricity and $\mathrm{CO}_{2}$ emissions in simplified way.

\section{References}

[1] International Renewable Energy Agency-IRENA (2012) Prospects for the African Power Sector, Abu Dhabi

[2] East African Community-EAC (2009) Regional Strategy on Scaling up Access to Modern Energy Services. East African Community (EAC), International Conference Centre (AICC), Arusha.

[3] East African Community-EAC (2011) East Africa, Development Strategy. East African Community (EAC), Arusha.

[4] www.irena.org.2013

[5] International Energy Agency-IEA (2014) Africa Energy Outlook, A Focus on Energy Prospects in Sub-Sahara Africa. World Energy Outlook Special Report, International Energy Agency, Paris.

[6] International Renewable Energy Agency-IRENA (2015) Africa Power Sector, Planning and Prospects for Renewable. Synthesis Report, International Renewable Energy Agency, Abu Dhabi.

[7] http://databank.worldbank.org/data/reports.aspx?source=2\&series=EG.ELC.PETR. S\&country 
[8] http://databank.worldbank.org/data/reports.aspx?source=2\&series=EG.ELC.FOSL. ZS\&country

[9] IEA (2002) World Energy Outlook: Energy and Poverty Special Issue. International Energy Agency, Paris.

[10] IEA (2003) Energy Balances of Non-OECD Countries, 2000-2001. International Energy Agency (IEA), Paris.

[11] EIU (2003) Uganda Country Profile, 2003. Economist Intelligence Unit, London.

[12] Denton, F. (2002) Gender: The Missing Link to Energy for Sustainable Development.

[13] Gustafson, D. (2001) The Role of Wood-Fuels in Africa. Proceedings of the African High-Level Regional Meeting on Energy and Sustainable Development for the Ninth Session on the Commission on Sustainable Development, UNEP Collaborating Centre on Energy and Development, Denmark.

[14] Misana, S.B. (2001) Gender Concerns in Accessing Energy for Sustainable Development. Proceedings of the African High-Level Regional Meeting on Energy and Sustainable Development for the Ninth Session on the Commission on Sustainable Development, UNEP Collaborating Centre on Energy and Development, Denmark.

[15] ESMAP (2003) Energy and Poverty: How Can Modern Energy Services Contribute to Poverty Reduction? Proceedings of a Multi-Sector Workshop, Addis Ababa, 23-25 October 2002.

[16] Karekezi, S. and Kimani, J. (2002) Status of Power Sector Reform in Africa. Energy Policy, 30, 923-945.

[17] Smith, K.R. (1991) Improved Biomass Cookstove Programs: A Global Evaluation. The Health Effect of Biomass Smoke: A Brief Survey of Current Knowledge, No. 4, Environment and Policy Institute, Hawaii.

[18] Smith, K.R. (1994) Health, Energy, and Greenhouse-Gas in Household Stoves. Energy for Sustainable Development, Vol. 1, International Energy Initiative, Bangalore. 